\title{
Juan Rafael Allende y su diálogo con la novelística social-picaresca*
}

Fecha de recepción: 15 de septiembre de 2014

Fecha de aprobación: 28 de noviembre de 2014

\section{Resumen}

En el presente ensayo se propone una lectura de las novelas Memorias de un perro escritas por su propia pata ${ }^{1}$ V Vida y milagros de un Pije $e^{2}$ del autor chileno Juan Rafael Allende (1848-1909) iguiendo las directrices de la literatura social propuesta por Edward Said y observando a su vez el diálogo que se establece con la picaresca española de los siglos XVI y XVII, a saber, la apropiación y el aprovechamiento que el autor hace de la poética de dicho género para conectarse a la actualidad más inmediata y poner en tela de juicio las instituciones de poder y sus dogmatismos

Palabras Clave: Juan Rafael Allende, Edward Said, crítica social, sátira, picaresca.

*El presente artículo de reflexión se enmarca dentro de una tesis de Magíster en Literatura en la Pontificia Universidad Católica de Chile. La tesis tiene como objetivo establecer los nexos que unen la Picaresca de Allende a la Picaresca Española de los siglos XVI y XVII y ahondar en su significancia para la construcción del imaginario popular chileno del siglo XIX.

1 Publicada por primera vez en el periódico Poncio Pilatos entre julio y septiembre de 1893. Juan Uribe Echeverría señala que Memorias de un perro escritas por su propia pata es, sin duda, la novela mejor lograda de Allende, en la que se percibe la influencia del folletín Primeras aventuras del maravilloso perro Cuatro Remos y también de los personajes cervantinos Cipión y Berganza. Véase Prólogo a Juan Rafael Allende, La república de Jauja. Valparaíso: Ediciones Universitarias, (sin fecha), p. 9.

Guillermo Rojas destaca el valor de Memorias de un perro escritas por su propia pata en su ensayo La novela picaresca en Chile, catalogándola como la mejor novela picaresca de la historia nacional. Véase Cuentistas Chilenos y otros ensayos, Santiago: Cultura, 1936, pp. 104-105.

2 Publicada por primera vez en el periódico Poncio Pilatos entre noviembre de 1893 y marzo de 1894. Acorde a Juan Uribe Echeverría esta novela se puede comparar a Las aventuras de un pije de Víctor Torres Arce publicada en 1871 con marcada influencia del Quijote de la Mancha de Cervantes. . Véase Prólogo a Juan Rafael Allende, La república de Jauja. Valparaíso: Ediciones Universitarias, (sin fecha) p. 11.

Citar: Carvajal, C. (julio-diciembre de 2015). Juan Rafael Allende y su diálogo con la novelística social-picaresca. La palabra, (27),147-158.

\section{Carolina Carvajal}

Pontificia Universidad Católica de Chile

Fctcarvaj@uc.cl

*Licenciada en Letras Hispánicas, Pontificia Universidad Católica de Chile (2005). Diplomada en la enseñanza de español, Pontificia Universidad Católica de Chile (2006). Experto Universitario en la enseñanza de español, UNED, España (2009), Tesista de Magíster en Literatura, Pontificia Universidad Católica de Chile (2014). Desde 2013, profesora de Lenguaje, Pontificia Universidad Católica de Chile. 


\section{Juan Rafael Allende and his dialogue with the social-picaresque genre}

\section{Abstract}

This article analyzes the novels Memorias de un perro escritas por su propia pata y Vida y Milagros de un pije [Memories of a Dog Written with His Own Paw and Life and Miracles of a Snob] by the Chilean author Juan Rafael Allende (1848-1909).This study takes into account the guidelines of social literature proposed by Edward Said, as well as an analysis of the dialogue between these novels and their Spanish counterpart from the XVI and XVII centuries; the appropriation and use that the author makes of the poetics of the picaresque genre, connecting it with the immediate present, and using it to question institutions of power and their dogmatism.

Key words: Juan Rafael Allende, Edward Said, social criticism, satire, picaresque.

\section{Juan Rafael Allende et son dialogue avec l'étude du roman socio-picaresque}

\section{Résumé}

Dans cet essai, je me propose d'analyser les romans Memorias de un perro escritas por su propia pata et Vida y milagros de un Pije [ Mémoires d'un chien écrites par sa proprepatte et vie et miracles d'un snob] de l'auteur chilien Juan Rafael Allende (1848-1909), en m'appuyant sur les travaux d'Edward Said concernant la sociologie de la littérature. Nous observons également le dialogue qui s'établit avec le genre picaresque espagnol du XVIème et du XVIIème siècles. En effet, nous nous penchons sur la manière dont l'auteur s'approprie et utilise la poétique de ce genre pour se connecter à l'actualité la plus immédiate et remettre en question les institutions de pouvoir et leurs dogmatismes.

Mots clés: Juan Rafael Allende, Edward Said, critique sociale, satire, picaresque. 


\section{Juan Rafael Allende y su relación con la picaresca}

Sobre la picaresca como género literario hay bastantes divergencias que no constituyen un tema de discusión en este ensayo, no obstante me parece pertinente que nos refiramos brevemente a algunas concepciones que permitan identificar trazos de este género en la novelística de Juan Rafael Allende. Cabe señalar que no habiendo tenido este género un mayor desarrollo en Chile durante el siglo XIX ${ }^{3}$ captó el interés de nuestro autor seguramente por constituirse como un proceso dinámico y flexible, tal como lo destaca Fernando Carreter, donde los artificios del género le permiten al escritor tomar una posición frente a la creación literaria de sus contemporáneos y frente a los sucesos históricos de su tiempó ${ }^{4}$.

De igual manera, una conexión no lejana entre la picaresca $\mathrm{y}$ otros géneros agrupados en el dominio de lo cómico-serio, como la sátira menipea, el simposio, el diálogo en el umbral, entre otros, que se penetran y se enriquecen entre sí compartiendo una cosmovisión carnavalesca, una libertad temática y una fantasía experimental que abunda en la novelística de Allende y que tal como señala Mijail Bajtín (1986), a propósito de la poética de Dostoievski, están al servicio de la puesta a prueba de una idea o "verdad" (p.162). En Allende, tanto la influencia del lenguaje picaresco, como la visión carnavalesca del mundo al revés le permiten apreciar con rebeldía cívica el espíritu de fin de siglo y moralizar sobre diversos aspectos de la modernidad que le son del todo cuestionables.

En su texto Para la revisión del concepto "novela picaresca", Fernando Carreter (1970) expone tres hallazgos constitutivos del género que se pueden sintetizar así: autobiografía de un desventurado, servicio a varios amos como pretexto para la crítica y relato como explicación de un estado final de deshonor (p. 206).

Sin duda, la novelística picaresca de Allende, a la cual habría que sumar además de las novelas ya citadas, Historia de un suplementero (1894) y parte de su autobiografía incompleta titulada Historia auténtica de las pellejerías y andanzas de Juan Rafael Allende, relatadas por él mismo y escritas con la única pata que le queda (1904) no se apega fielmente a los hallazgos de Carreter, pero sí establece un vínculo con el lenguaje proveniente de la picaresca española de los siglos XVI y XVII, para adoptar de ella, acorde a los estudios del historiador chileno Maximiliano Salinas (2006), el habla desbocada, la reivindicación del deshonrado y la denuncia de una tajante división de clases sociales (p. 235). Siguiendo las coordenadas del Lazarillo de Tormes y el Guzmán de Alfarache, los personajes de Allende se abocan al examen de tipos y estados sociales, pero extendiendo la crítica a toda la sociedad.

Se observa, sin nebulosas, el gesto político que hay detrás de la elección de ciertas características del género picaresco, especialmente del primer elemento mencionado por Carreter y que es un rasgo que tienen en común

\footnotetext{
3 Guillermo Blanco en su estudio sobre la novela picaresca en Chile rastrea creaciones como Las aventuras de un pije, 1871, de Pedro Urdemales (Victor Torres Arce), Historia de Pedro Urdemales, 1885, obra anónima y Memorias de un roto, 1899, obra desaparecida. Blanco asegura que se trata de novelas que operan como simple imitación servil y afectada de los modelos clásicos, pobres de estilo y de inventiva. Veáse Cuentistas Chilenos y otros ensayos, Santiago: Cultura, 1936, pp. 101-103.

4 El historiador Maximiliano Salinas apunta en su texto Juan Rafael Allende "el pequén” y los rasgos carnavalescos de la literatura popular chilena del siglo XIX que la literatura bien valorada en Chile a fines del siglo XIX era aquella apolínea y mesurada, apegada a la tradición clásica y que versaba contra la risa y el amor sensual. Ejemplo son las obras de Juan Egaña y Domingo Arteaga. Allende, por otro lado, se muestra constantemente comprometido con el devenir socio-político de su nación, así incluye en sus novelas referencias a la Guerra del Pacífico, la derrota del presidente Balmaceda, la Batalla de Placilla, el proceso de modernización, la riqueza del salitre, entre otros sucesos.
} 
las novelas tratadas en este ensayo: el relato autobiográfico. ¿A quién da el autor la voz? Pues a una serie de subjetividades nacientes y proliferantes en el Santiago de fines del XIX: el roto chileno ${ }^{5}$ el pije $^{6}$, y en otras de sus obras lo hará con el gañan ${ }^{7}$, con el niño huérfano, con los muertos, entre otros. Una acotación interesante hace Juan Carlos Rodríguez (2001) en su texto La literatura del pobre sobre las nuevas relaciones que surgen del primer mercado capitalista, donde se abre "una serie discursiva donde por primera vez se ve al pobre no como pobre de Dios sino como hecho social $y$, por tanto, como algo que puede inscribirse en un discurso" ( $p$. 23). Se trata entonces de hacer hablar a aquellas voces pobres y marginadas, comúnmente silenciadas en un marco de modernización europeizante que opera con la expulsión de todo lo considerado "popular".

¿Qué lugar le cabe al "yo" autobiográfico en medio de la mundaneidad textual, es decir de la conexión de los textos al entorno social? El cuestiona- miento anterior puede hallar una respuesta en la imposibilidad de una conciencia única para el hombre que narra una historia, aunque sea esta su propia historia. Se puede hablar con certeza de la imposibilidad del yo como lenguaje aún en el relato autobiográfico de la picaresca ya que el testimonio personal del pícaro llega en realidad como la expresión viva de todo un pueblo o comunidad.

Ligar el arte a la vida del pueblo será el eje de toda novelística social. Edward Said (2001) postula que el texto no debe alejarse de la cotidianeidad y que debe contaminarse de todos aquellos asuntos que el sistema social no le ha autorizado. Pero a partir de Said se puede ir aún más lejos. No se constata solamente que un texto es mundano y que da a conocer el sufrimiento de un pueblo a través de un yo narrador-protagonista y testigo de la historia, sino que se tiene el desafío humanista de vincular ese dolor a otros dolores, porque solo así, a través de esa empatía, se podrá darle un vasto alcance a los acontecimientos humanos:
A estas tareas terriblemente importantes de representar el sufrimiento colectivo del propio pueblo, dar testimonio de sus afanes, reafirmar su presencia duradera y reforzar su memoria, debe añadirse algo que, en mi opinión, solo un intelectual tiene la obligación de hacer. Después de todo, muchos novelistas, pintores y poetas, como Manzoni, Picasso o Neruda, han encarnado la experiencia histórica de sus pueblos respectivos en obras estéticas, que a su vez han terminado siendo reconocidas como grandes obras maestras. Al intelectual le incumbe, creo yo, la tarea de universalizar explícitamente la crisis, de darle un alcance más humano, más amplio a los sufrimientos que haya podido experimentar una nación o raza particular, de asociar esa experiencia con los sufrimientos de otros (p. 28).

De este modo, el yo autobiográfico de la picaresca no cesará de multiplicarse y de transformarse en espejo de otredad.

\footnotetext{
5 Este término ha sido usado en Chile para designar a una persona de origen urbano y pobre, pero en el siglo XIX adquiere una connotación clasista y peyorativa. En su diccionario de chilenismos de 1875, Zorobabel Rodríguez define roto como gente de última clase con sus acepciones castizas: andrajoso y zarrapastroso.

6 Zorobabel Rodríguez, en su diccionario de chilenismos de 1875, define al pije o futre como un mozo de medio pelo. En su artículo "Las andanzas de Juan Rafael Allende por la ciudad de los 'palacios marmóreos' y las cazuelas deleitosas. Santiago de Chile 1880-1910" publicado en la revista Historia social y de las mentalidades No XIII (2009) el historiador Daniel Palma define al pije como un personaje urbano propio de finales del siglo XIX, proveniente, en su mayoría, de familias adineradas venidas a menos y caracterizado por la ostentación y el derroche como falsos atributos para medrar y sobresalir en la sociedad.

7Término de origen discutido, se utilizaba en Chile en el siglo XIX para hacer referencia al peón o jornalero.
} 
En su estudio El pícaro bablador, Gonzalo Sobejano (1975), dice respecto a dicho personaje: "El pícaro habla mucho, y habla -con típica frecuencia- para censurar las acciones ajenas y aun las propias; locuacidad, pues, y critica, o sea: locuacidad critica” (p. 467). Es así, como en un marco de deleite festivo, los picaros de Allende (Rosalindo y Can-pino) se expresan a través de diversos recursos retóricos sobre el recelo que les provocan los totalitarismos y la intervención religiosa en la política nacional. La influencia de una obra fundacional del género como el Lazarillo de Tormes, se observa en la prosa de Allende, especialmente en aquello que se podría llamar "clerofobia", es decir el hablar anticlerical punzante del cual ya se habló anteriormente. Ambos personajes de Allende miran hacia los bajos fondos, y provienen a la vez de ellos, confiesan sus males y se yerguen como pícaros aleccionadores dentro de un universo caótico. Vienen a enriquecer la locuacidad crítica de los personajes, los métodos de la sincresis (confrontación de distintos puntos de vista frente a un suceso) y la anácrisis (provocación de la palabra por la palabra), ambos provenientes de lo cómico-serio y muy utilizados por los géneros carnavalizados como la sátira menipea y el diálogo socrático en su fase inicial.

Diamela Eltit (2010), investigadora y académica chilena, describe la picaresca como una literatura de sobrevivencia, espacio en el cual el pícaro es "aquel que lee la sociedad de su tiempo y sortea la violencia que lo daña y que lo oprime" (p. 21). No cabe duda que el habla picaresca de Allende forma parte de la materialización de un proyecto social y político ${ }^{8}$ y es en este espacio donde viene a lugar su relación con las ideas que más de un siglo después desarrollaría el crítico palestino Edward Said. En su prólogo a La República de Jauja, Juan Uribe Echeverría (s.f.) señala respecto a dicha pieza teatral: "(en ella) Afloran constantes históricas que todavía persisten en el desarrollo de las democracias de Hispanoamérica. Obra de actualidad que supera las fronteras nacionales y parece escrita en nuestros días" (p. 31). Es precisamente esa característica de actualidad viva y cercana que Allende hereda de la menipea, su pluma atemporal y su interés por lo mundano, que hace prudente vincular su obra a los postulados de Edward Said respecto de una creación literaria socialmente comprometida.
Lo mundano y lo secular en la picaresca de Allende

En mayo 6 de 1875 daba yo a luz el primer número de "El Padre Cobos"; veinticuatro años de periodismo anticlerical y democrático; veinticuatro años de lucha diaria incesante, sin más descanso que mis gravísimas enfermedades y mis carcelazos y persecuciones. Veinticuatro años contra el clero, contra la oligarquía chilena y contra los pícaros de todos los partidos políticos (Uribe, sin fecha, p. 9).

Esta reflexión extraída de la autobiografía de Juan Rafael Allende, quizá sea una buena entrada al pensamiento de Edward Said (2004) sobre la naturaleza de la creación literaria: "En mi opinión los textos son mundanos, son hasta cierto punto acontecimientos, e incluso cuando parecen negarlo, son parte del mundo social, de la vida humana y, por supuesto, de momentos históricos en los que se sitúan y se interpretan" (p. 15). Allende lee su entorno con lo que Said llama Conciencia Crítica. Igualmente esa conciencia critica se ha de transformar en un instrumento de cuestionamiento al orden imperante y

8 Es importante señalar que paralelamente a su creación literaria, Juan Rafael Allende fundó el Partido Demócrata en Chile en 1887. Sus constantes intervenciones en la vida política del país lo llevaron a ser perseguido, encarcelado, saqueado y condenado a muerte en 1891. 
a las definiciones inamovibles que se tiende a observar sin sospechas.

Son interesantes básicamente dos conceptos que se dan la mano y se potencian el uno al otro. Se trata de la mundaneidad y la secularidad de los textos. Se puede afirmar que la picaresca de Allende es mundana en cuanto el autor se hace cargo de la realidad que le rodea, siendo sus textos entidades no completas en sí mismas, es decir que para su interpretación y comprensión es necesario establecer una conexión con factores externos. Téngase por factor externo de la novelística de Allende el proceso de modernización que inicia en Santiago en 1870 y que opera con la marginación de la cultura popular. De dicha marginación derivarán fatales consecuencias para la literatura, el goce corporal y las festividades. Hay que tener en cuenta que en Santiago aún se celebraba el Carnaval de la Chaya, pero al iniciar la modernización comenzó una seguidilla de prohibiciones de carnaval, hasta llegar a 1903 cuando se publicaban listas de detenidos por participar en dichas celebraciones. La actitud de Allende frente a la mesura y el control que imponía la autoridad será de un talante reivindicador de lo que el autor mismo entiende por "chileno" y "popular".

Así mismo es posible aseverar que la picaresca de Allende es secular en cuanto se aprecia una mirada incrédula ante los parámetros que el mundo oficial usa para presentarse; mostrándose como no sujeto a análisis. La mirada secular de Allende sí admite el análisis y la redefinición de lo que se muestra en calidad de absoluto. Respecto a la crítica secular de los textos, Said (2004) señala:

Con su sospecha hacia los conceptos totalizadores, su descontento ante los objetos reificados, su intolerancia hacia los gremios, los intereses particulares, los feudos imperializados y los hábitos mentales ortodoxos, la crítica es más ella misma y, si se pueden permitir la paradoja, más distinta de sí misma en el momento en que empieza a convertirse en dogma organizado (pp. 46-47).

¿A qué se enfrenta la propuesta de crítica consciente y secular de Said? Se enfrenta a una cultura concebida de modo muy similar a la concepción de una autoridad. Como apuntaba Dostoievski (2004) en Pensamientos anotados, se trata de una cultura poderosa y excesiva que está muy lejos de ser nuestra aliada: "La cultura excesiva no siempre es cultura verdadera o justa. La verdadera cultura no sólo no es enemiga de la vida, sino que está siempre de acuerdo con ella, ofreciéndole nuevas revelaciones que descubre en la vida misma" (p. 85). Desde su posición encumbrada, la cultura domina, legitima, prohíbe y valida. "Lo más importante en la cultura es que se trata de un sistema de valores que empapa de arriba abajo casi todo lo que encuentra en su ámbito" (Said, 2004, p. 21). Allende se hace cargo en sus novelas de denunciar esta cultura oficinal que se ocupa de marginar las manifestaciones populares. En sus escritos, acusa la educación agringada de los colegios, la falta de espacios de recreación para el pueblo, el afrancesamiento de la comida burguesa, los dogmas que transmiten las universidades. Como señala Maximiliano Salinas, Allende quiso destacar el valor y la presencia real y auténtica del pueblo chileno en medio de una cultura de élite que constantemente lo empujaba hacia los márgenes.

Rosalindo y Can-Pino están permanentemente fuera del mundo oficial, excluidos del sistema de discriminaciones y evaluaciones que Said denomina cultura, y aunque forman parte ocasional de él, su incursión en las instituciones de poder (iglesias y organismos militares) les confirma paradójicamente que no pueden pertenecer, que no hay afiliación posible:

La primera vez que me vistieron de militar me sentí hombre, y miré con cierto orgullo de los demás quiltros y perros del conventillo. ¡Yo, un 
pobre perro, había sentado plaza de soldado! ¡Cuánto debía yo más tarde de arrepentirme por haber abrasado aquella carrera! (Allende, 2002, p. 11).

Cuando Said reflexiona sobre cultura y sociedad habla de la base material donde la cultura extiende su influencia a través de sus grandes hombres, a través de la transmisión de una norma privilegiada y la veneración de $l o$ mejor de nosotros. En términos de Said se podría hablar de literatura de complicidad orgánica, es decir aquella que está al servicio de las instituciones dominantes, para ratificar y difundir su poderío. Está presente desde luego el temor por parte de las autoridades a que el pueblo sepa, es decir a que se instruya debidamente. Es por eso que, paradójicamente, y tal como apunta el crítico palestino, la cultura no alcanza a todos a quienes domina. Ese temor también es capturado por Said (2004) en Representaciones del intelectual, donde se refiere al texto Culture and Anarchy de Mathew Arnold:

De allí la necesidad implícita que sienten los intelectuales de sosegar a las personas, de mostrarles que las mejores ideas y las mejores obras de la literatura representaban una manera de pertenecer a una comunidad nacional, lo que a su vez excluía lo de hacer aque- llo que a uno le guste (p. 20).

Cuando aprende a escribir, Can-Pino hace una alusión burlesca a la escritura no contaminada, que permanece en un mundo lejano y apacible: "Seis meses más tarde (...) escribía, si no como un eximio calígrafo, al menos mucho mejor que don Benjamín Vicuña Mackenna” (Allende, 2002, p. 67). La crítica en Allende es punzante y a la vez humorística, un ejemplo de ello se aprecia en la disminución que sufre la seriedad académica a través de la agudeza de Can-Pino en sus clases de latín:

\section{Mientras tanto, a mí me hacían concurrir a las clases de latín y de teología; pero, si he de ser franco y modesto, diré que después de las clases, me quedaba tan en ayunas como antes de ellas. Un día, el maestro de latín me hizo salir al medio de la sala y me preguntó: Quid est canis inter nos? (¿quién es perro entre nosotros?); y yo respondí tres veces en francés: Moá, moá, moá (Allende, 2002, p. 28).}

\section{Allende anticlerical y carnavalesco}

En Memorias de un perro escritas por su propiapata se tiene a un pícaro que pasa a formar parte del mundo al cual satiriza. Como fiel representante de la sátira carnavalesca, se sitúa dentro del espacio que critica, tal como señala Mijail Bajtin en su estudio La cultura popular en la Edad Media y el Renacimiento. Nos encontramos pues con un perro que no solo tiene por amo a un militar, sino que él mismo se hace militar, así como más adelante, cuando llegue a servir a los frailes de la Orden de San Francisco, se ordenará fraile aun contra su voluntad con un discurso donde se perciben claramente los ecos de lo cómico-serio:

Queridos hermanos, yo no puedo ser fraile porque no tengo vocación para el oficio ni puedo hacer votos solemnes por las siguientes razones: $1^{\text {a }}$ no puedo hacer voto de pobreza porque no me siento con ánimo de ser pobre, y aún recuerdo el placer con que me exhibía en el circo con mi traje galoneado de capitán; $2^{a}$ no puedo hacer voto de humildad, porque si alguien me pisa una pata, no pondré la otra para que me la pisen también, y en esto imito a mis paisanos los presbíteros, que no ponen la mejilla derecha para que les emparejen la sangría, cuando les dan una bofetada en la mejilla izquierda, sino que sacan el revólver y le dan un balazo al que los abofeteó, y $3^{\mathrm{a}}$, y menos puedo hacer el voto de castidad, porque en viendo una perrita de buenos bigotes como mi inolvidable 
Musidora, soy perro al agua, capaz de jugarle una mala partida hasta al mismo respetable público. No, señor, no tengo vocación para la vida monástica (Allende, 2002, p. 23).

Este discurso que el protagonista nunca llega a pronunciar, pues no tiene el don de palabra, será la entrada a una serie de acusaciones sobre la vida religiosa que no cesarán a lo largo de toda la novela y que tienen relación con la ya mencionada habla anticlerical común en la picaresca. Ténganse por ejemplo las secretas y enredadas aventuras amorosas de frailes y beatas, la simulada homosexualidad al interior de los monasterios, la intervención permanente de la iglesia en la vida política del país, incluso en los saqueos ocurridos en la época, la preponderancia del dinero al interior de las instituciones católicas y el ayuno anticarnavalesco. Con una lengua que tiende al rebajamiento, al traslado de lo alto hacia lo bajo, es frecuente hallar en Allende (2002) alusiones como las siguientes: "La beata vivía sola, sin otro compañero que un gato romano, a quien desde los primeros momentos le tuve mala voluntad. ¡Era romano, y yo detesto todo lo que viene de Roma!” (p. 8). En el mismo marco, vemos que diversos eventos de ambas novela, por mundanos que parezcan, van a conformar un espacio para el acoso anticlerical: "Bueno...yo quiero ver a mi hijo... porque no soy como los presbíteros y los frailes, que los niegan" ( $p$. 45) dice Can-Pino al enterarse de su paternidad. "Era hermana de fraile, y no podía ser buena" (p. 152) reflexiona Rosalindo cuando su mujer lo abandona. Actualizando el género paródico y burlesco de los testamentos de animales, popular en la Edad Media, hace redactar a Can-pino:

En el nombre del pavo, del buitre, del jote y del pequén, amén (...) $1^{\circ}$ Quiero que mi hijo Torquemada siga en casa de don Querubín y que, al fallecimiento de este protector de la raza canina, entre al servicio de un liberal y jamás al de una beata, y mucho menos al de clérigos o frailes, que son personas que nos obligan a hacer cosas que están reñidas con nuestra dignidad. (...) $6^{\circ}$ Lego mi arestín al fray Hilarión (...) $12^{\circ}$ Lego mis tripas a la Curia eclesiástica para que haga de ellas cuerdas romanas con que ahorcar liberales (p. 73).

\section{En Vida y milagros de un} pije, la intervención religiosa en la política nacional será develada extensamente al incluir Allende tres capítulos referentes al saqueo ocurrido en Santiago en 1891 con motivo de la derrota del Presidente José Manuel Balmaceda: “QQué cosa tan bella es el saqueo de una ciudad! Es un espectáculo que merece ser visto, siquiera sea porque no todos los días se presenta esa manifestación de la cultura y la religiosidad de un pueblo" (p. 124). Allende, con una amarga ironía, hace una descripción festiva del saqueo donde participan todas las clases sociales y el himno patrio se escucha en las calles en la voz de matronas y doncellas. No obstante, el autor deja entrever que no se trata de una "plaza carnavalesca", sino, todo lo contrario, de un espacio anticarnavalesco donde se acentúan los odios y las divisiones sociales. No tarda entonces, a través de Rosalindo, en poner antes nuestros ojos el verdadero horror del suceso:

Y allá, en los hogares saqueados, padres que agonizaban, esposos que se retuercen, madres que se desmayan, niños que lloran de terror, vírgenes que gimen de vergüenza, hogares que desaparecen; y en los aires, cerniendo sus alas, el genio de la discordia, y el buitre de la Religión Católica, abriendo el pico y aprestando las garras para devorar a los vencidos (p. 126).

La imagen grotesca del buitre (como alegoría del Catolicismo) devorando a los débiles, es una reacción contra una estrecha unión entre la política y la iglesia que se consolidó con la constitución política de 1833, la cual tenía 
un marcado carácter antiliberal.

A partir de entonces se produjo un suceso de mayor trascendencia: la feliz unión conyugal entre el nuevo espíritu burgués y la vieja herencia del catolicismo romano. Lo tradicional del sistema cultural español y lo moderno del sistema comercial británico se fusionaron en el ordenamiento conservador que dio lustre y prestigio a Chile en el siglo XIX (Salinas, 2001, p. 7).

\section{La ecfrástica descripción del} saqueo es también una oportunidad para desnudar ante el lector la imagen de un hombre subterráneo, sometido y vigilado. Este hombre subterráneo sufre, según lo describe Dostoievski, un desmoronamiento que no es solo social o económico, sino también moral. Así, nos encontramos con un honrado artesano que ante la palabra mágica saqueo se va, herramienta en mano, a colaborar con el desalojo de los hogares. El mismo Rosalindo, aturdido por la turba y seducido por el dinero fácil, va a tomar parte sin remordimientos.

Acogiéndonos a los estudios de Mijaíl Bajtín (1990) en La cultura popular en la Edad Media y el Renacimiento, podemos decir que Allende recoge los principios de la vida material y corporal desarrollados por el autor ruso: "imágenes del cuerpo, de la bebida, de la satisfacción de las necesidades naturales y la vida sexual" (p. 23) pueblan las novelas del autor chileno como una forma de contradecir el discurso oficial sobre el necesario control y mesura del cuerpo a fines del siglo XIX. Una interesante referencia es lo expuesto por el canónigo y consejero de Estado Francisco de Paula Toforó en 1876:

La sensualidad es una afección criminal por los placeres contrarios a la castidad cristiana; es un deseo desarreglado de los placeres carnales e impuros. Este es el pecado que los voluptuosos quieren hacernos mirar como una culpa muy leve... Pero, la sensualidad no es culpa leve, porque para castigarla hizo el Señor que pereciese el mundo en el diluvio universal;... No os hagáis ilusión: no solo los pecados consumados de impureza son los que conducen a la eterna perdición, sino también la lectura de un libro obsceno, una canción impura, un discurso deshonesto, una acción, un pensamiento o un simple deseo consentido en esta materia, es bastante para perder vuestra alma y causar su eterna desgracia (Salinas, 2001, p. 69).

Desde su mirada transgresora, Allende incorpora a sus novelas la idea del placer sensual en los amoríos, infidelidades y conquistas de sus personajes, especialmente aquellos vinculados a instituciones religiosas. Con motivo de la muerte de Can-Pino hay un memorial en el que se lee la siguiente inscripción: "Durante su peregrinación por la vida no tuvo otro momento de felicidad que aquel en que por primera vez estrechara con sus patas delanteras el talle esbelto de la simpática Musidora" (Allende, 2002, p. 81).

La idea de cuerpo carnavalesco está indivisiblemente ligada al tema de la comida. En su estudio sobre la obra de Rabelais, Mijaíl Bajtín (1990) señala que el comer y beber son una de las manifestaciones más importantes del cuerpo grotesco. Para el teórico ruso, el cuerpo carnavalesco durante la celebración de una comida portentosa engulle al mundo antes de ser engullido por él. "El cuerpo se evade de sus límites; traga, engulle, desgarra el mundo, lo hace entrar en sí, se enriquece y crece a sus expensas" (p. 253). Dicho en otras palabras, a través del acto de masticar y tragar al mundo, el hombre triunfa aunque sea momentáneamente sobre la violencia que lo oprime en su vida cotidiana. Allende, en su afán de reivindicar la noción de cuerpo carnavalesco imprime en cada comida que tiene lugar en sus novelas un tono 
alegre y triunfante. En ambas novelas los personajes disfrutan de las comidas abundantes y el placer que estas les reportan. En Vida y milagros de un pije hay una serie de alusiones como las siguientes: "Y empezó una comida heliogabálica" (p. 89), "Almorcé como su hubiera tenido muchas hambres atrasadas" (p. 98) "Aquella burla y nuestra ganancia del día las celebramos con una opípara cena" (p. 113), "Y se acordó celebrar el triunfo de la revolución con un banquete heliogabálico" (p. 131) "Comí y bebí para quince días" (p. 134), "Comimos y bebimos como unos Heliogábalos” (p. 155). A través de las imágenes de banquetes y cenas abundantes, Allende está criticando de paso la imposición de la cuaresma y el ayuno por parte de la iglesia y la élite conservadora, como también está denunciando el problema del hambre: "La falta de comida, la escasez alimentaria en el pueblo fue interpretada como una negación de la relación fraternal y solidaria que debería existir necesariamente entre los miembros de una colectividad humana” (Salinas, 2004, p. 221).

El control sobre el cuerpo en época de Allende, va a tener como uno de sus principales focos a la mujer, quien estará en permanente vigilancia. En el Manual de la moral del Presbítero Lorenzo Robles, que data de algunas décadas anteriores a Allende pero que tendrá sin embargo una longeva vigencia, se habla de la conducta de la mujer en los siguientes términos:

En jeneral la conducta de una mujer debe ser más reservada que la de un hombre... El decoro ha establecido para el bello sexo leyes mucho más severas que para los hombres; pues si éstos disfrutan de algunas excepciones de las reglas generales, para las mujeres no hai excepción alguna (Salinas, 2001, p. 73).

Allende, ciertamente conocedor de este y otros manuales de la decencia femenina, va a poblar su picaresca de mujeres gozadoras, infieles, que corren tras las aventuras y el placer del dinero y los amores prohibidos. En Memorias de un perro escritaspor su propia pata nos encontramos con Irene, mujer casada, que por las noches escapaba de casa y se colaba en el claustro de un convento franciscano para pasar las noches con sus dos amantes: el Fray Hilarión y el Padre Maestro. Can-Pino, descubre las andanzas de esta animada mujer al encontrar sus zapatos a los pies de la cama del fraile que lo tomó a su servicio, pero este, con mucha agudeza, se excusa ante su superior advirtiendo que los zapatos son un recuerdo de su fallecida madre.

Me tentó el Diablo por averiguar si todos los padres eran cariñosos con la memoria maternal. Y por la ventana me colé sigilosamente a todas las celdas. ¡Todos tenían al pie del lecho un par de recuerdos de la mamá! ¡Y el provincial tenía dos pares! ¿Qué misterio era ése? ¿Acaso el provincial había tenido dos mamás? ¡Qué amor filial tan parejo! $i Y$ yo no tenía ni un zapatito siquiera de la grandísima perra de mi madre! (Allende, 2002, p. 27).

La reivindicación del cuerpo carnavalesco, entendido en términos bajtinianos como un cuerpo abierto, inacabado y en constante interacción con el mundo, va a ser parte fundamental del ya mencionado contra-discurso de Allende, discur-

9 El término heliogábalo significa persona dominada por la gula. Hace referencia al emperador romano Heliogábalo quien reinó desde 218 a 222. Heliogábalo fue controversial por ignorar las tradiciones religiosas y reemplazar el culto a Júpiter por el culto a un Dios de carácter menor. También causó polémica por sus numerosos matrimonios, su transexualidad y por prostituirse tanto en tabernas como dentro del mismo palacio imperial. Algunos historiadores como Edward Gibson lo recuerdan como un hombre que "se abandonó a los placeres más groseros y a una furia sin control”. Véase el capítulo 6 de Gibbon, Edward, Decline and Fall of the Roman Empire. 
so enfrentado a la proliferación de manuales de comportamiento urbano, instrucciones para cristianos, entre otros documentos centrados en la vigilancia del cuerpo. Maximiliano Salinas (2001) nos señala en su texto $E l$ reino de la decencia que "El placer corporal fue tematizado en un sentido negativo como causa del desorden público o las calamidades públicas" (p. 68).

¿Cómo nos permite Said leer la Picaresca de Allende hoy?

El alcance que tiene la visión de Edward Said es relevante. Si el orden político y social está disponible para su cuestionamiento, entonces podemos exorcizarlo, destronarlo, releerlo y redefinirlo. Lo importante para Said, no será qué leemos, sino cómo lo leemos. Si alcanzamos la capacidad de abordar un texto, no desde el mundo lejano e indiferente, sino desde el mundo de los acontecimientos (tanto los acontecimientos del tiempo de escritura como los del tiempo de lectura), vamos a hacer de cada texto una forma viva. Desde Said (1996) es posible recuperar a Allende para abordar sus textos tal como lo hace Raymond Williams en $\mathrm{El}$ campo y la ciudad quien "no se centra en lo que esos poemas representan, sino en lo que son como consecuencia de las relaciones sociales y políticas en pugna" (p. 42). Abordar las novelas picarescas Memorias de un perro escritas por su propia pata y Vida y milagros de un pije tanto por lo que fueron en su época como por lo que pueden ser en la actualidad, y considerando el gesto político que subyace a la elección del lenguaje picaresco, es tener la posibilidad de darle una mirada secular y mundana a la transmisión y perpetuación de una cultura hegemónica

\section{Referencias}

Allende, J. A. (S.f.). La república de Jauja. Valparaíso: Ediciones Universitarias.

Allende, J. A. (2002). Memorias de un perro escritas por su propia pata y Vida y milagros de un pije. Santiago: Tajamar editores.

Bajtín, M. (1990). La cultura popular en la Edad Media y el Renacimiento. (J. Focart y C. Conroy, trad.). Madrid: Alianza.

Bajtín, M. (1986). Problemas de la poética de Dostoievski. México: Fondo de cultura económica.

Blanco, G. (1936). Cuentistas Chilenos y otros ensayos. Santiago: Cultura.

Carreter, F. (1968). Para la revisión del concepto "novela picaresca". México DF: Asociación internacional de hispanistas.

Dostoievski, F. (2004). Diarios de un escritor. Buenos Aires: Longseller. 
Eltit, D. (2010). Literaturas de la sobrevivencia. The clinic online. Recuperado de http://www.theclinic.cl/2010/06/01/literaturas-de-la-sobrevivencia/

Palma, D. (2009). Las andanzas de Juan Rafael Allende por la ciudad de los 'palacios marmóreos' y las cazuelas deleitosas. Santiago de Chile, 1880-1890. Historia social y de las mentalidades, 1(13), 123-157.

Rodríguez, J. C. (2001). La literatura del pobre. Granada: Comares.

Rodríguez, Z. (1875). Diccionario de chilenismos. Santiago: El independiente.

Said, E. (2004). El mundo, el texto y el crítico. (R. García Pérez, trad.). Barcelona: Debate.

Said, E. (1996). Representaciones del intelectual. (I. Arias, trad.). Barcelona: Paidós.

Salinas, M. (2001). El Reino de la decencia. Santiago: LOM Ediciones Ltda.

Salinas, M. (enero-junio 2004). Juan Rafael Allende, "el pequén" y los rasgos carnavalescos de la literatura popular chilena del siglo XIX. Historia, 1(37), 207-236.

Salinas, M. (enero-junio 2006). ¡Y no se ríen de este leso porque es dueño de millones!: El asedio cómico popular de Juan Rafael Allende a la burguesía chilena del siglo XIX. Historia, 1(39), 231-262.

Sobejano, G. (1975). Un perfil de la picaresca: el pícaro hablador. En: Studia Hispanica in honorem Rafael Lapesa III. Madrid: Gredos. 